\title{
Inquiry without standards: A reply to Hand
}

\author{
Laurance J Splitter \\ The University of Melbourne and the Education University of Hong Kong \\ laurance.splitter@unimelb.edu.au
}

\begin{abstract}
In this 'Reply', I am critical of several aspects of Michael Hand's paper 'Moral education in the community of inquiry'. I do not agree that such terms as 'standards' and 'directive teaching' are consistent with a proper understanding of inquiry generally, and philosophical inquiry, moral inquiry and community of inquiry, in particular. I also argue that the idea of openness, duly modified, remains central to all forms of inquiry, whether philosophical or otherwise. Finally, I cast doubt on Hand's characterisation of the distinctions between controversial and uncontroversial, on the one hand, and justified and unjustified, on the other, by reflecting critically on his own examples.
\end{abstract}

\section{Key words}

controversial, ethics/morality, inquiry, moral education, openness

\section{Introduction}

While sympathetic to some of what Michael Hand has written in his paper 'Moral education in the community of inquiry' (this issue), I do not think that his characterisation of the central concept of moral inquiry is adequate. This shortcoming vitiates his core claims relating to the place of what he calls 'directive teaching' within the context of the community of inquiry.

The use of terminology in the context of moral education is somewhat contentious. Even leaving aside the difference between 'ethics' and 'morals'/'morality', we should not take for granted either the nature of ethical/moral inquiry, or the relationship 
between what belongs in the classroom (moral education? ethical inquiry?), and what is part of philosophy (ethics? ethical theory? moral philosophy? ethical inquiry?).

\section{Ethical/moral inquiry and openness}

Hand (2020) defines moral inquiry as:

inquiry with children and young people into the justification for subscribing to moral standards. Moral inquiry is a matter of investigating the nature of moral standards, asking how subscription to such standards might be justified, and examining the strength of suggested justifications. (p. 4)

But what is the word 'standards' (which Hand uses to mean something like 'rules, prescriptions, findings, outcomes') doing here? In schematic terms, sticking fairly closely to his formulation, we could say that ' $X$ inquiry - i.e. inquiry into $X$ - is a matter of investigating the nature (meaning) of $X$, asking how claims/beliefs about $X$ might be justified, and examining the strength of suggested justifications ...'. Thus, mathematical inquiry investigates the nature of mathematics, asks how mathematical claims/beliefs might be justified, etc; and ethical inquiry investigates the nature of ethics, asks how ethical claims/beliefs might be justified, and examines the strength of suggested justifications. Elsewhere (Splitter 2020), I have characterised inquiry as involving a 'commitment to getting to the bottom of things while realising that the bottom is rarely, if ever, reached and, accordingly, there is always more work to do'. ${ }^{1}$ I think that my schematic description of inquiry is consistent with this general characterisation, because investigating the nature or meaning of $X$, finding out how $X^{\prime}$ 's claims are justified, and examining the strength of suggested justifications, are all ways of getting to the bottom of things regarding $X$, while realising that the bottom is rarely reached and more work may be needed. However, including the term 'standards' or an equivalent term produces an important shift in emphasis: i.e. schematically, 'investigating the nature/meaning of X's standards, outcomes or rules, asking how such standards, outcomes or rules can be justified, and examining the strength of suggested justifications of these standards, outcomes or rules'. This formulation assumes that the inquiry process is all about investigating outcomes which are known in advance. In particular, it is assumed that the outcomes of ethical

Splitter 2020 is, in part, a modification of the 2016 paper to which Hand refers. 
inquiry are known in advance and help to determine if the inquiry has been successful. With such a definition of ethical inquiry, it is not surprising that Hand can justify what he calls 'directive' moral education as a form of inquiry.

In the context of constructing curricula, determining course goals and objectives, and other practical tasks in which educators are engaged, the customary imperative to specify outcomes for each subject area and each grade level is difficult to avoid. Nevertheless, there is some tension between the specification of such outcomes and the ideals of the community of inquiry, insofar as the former threaten to close off or block the path to further inquiry. This tension is less acute when the curriculum in question is philosophy, where specific content outcomes-as opposed to the determination of conceptual understandings - cannot be specified in advance, simply because most of the 'Big' questions and answers of philosophy remain unsettled and contestable, even among the so-called experts. Concerning other subjects taught at school, I have previously suggested that there are ways in which teachers can preserve the sense of openness which characterises genuine inquiry, even when they 'know the correct answers'. Hand expresses his support for this idea, but I am not sure that I can support his support!

I am committed to the idea that inquiry in general - along with the questions which generate it-should be regarded by those who engage in it as open in an important sense. This is in line with the Pragmatist view of inquiry - also echoed by Lipmannamely, that it is a self-correcting practice, one which should not be blocked but, rather, followed wherever it may lead (Lipman 2003). If this is right, then it applies as much to philosophical and moral inquiry as to inquiry in those disciplines where the answers are regarded by the relevant experts as more or less settled. It also applies to forms of student inquiry, which is why I share Hand's criticism of the Question Quadrant, namely, that it implies that questions and responses in science and other settled disciplines do not constitute inquiry (although my criticism is stronger because I don't accept that these disciplines are closed). ${ }^{2}$ As Hand points out, I do believe that inquiry is sparked by questions which reflect certain dispositions among those inquiring, including the feeling or sense that matters are unsettled, i.e. unsettled from their perspective. However, Hand also asserts that when it comes to student inquiry again in philosophy as well as other areas-'Questions discussed in the CoI need not

2 In his original formulation of the Question Quadrant, Cam's third quadrant is labelled 'Closed Intellectual', 'One right answer', and 'Ask someone who knows the answer' (Cam 2006, p. 34). I agree with Hand that the examples offered there are hardly intellectual in nature. These labels don't apply readily to 'Big' questions in science, literature, etc. 
be open as long as they seem open to the pupils engaged in the inquiry. And it is simply a mistake to suppose that philosophical questions are open by definition' (2020, pp. 12-13) My point, however, was to affirm the openness of inquiry by shifting the object of openness from the subject matter (questions and answers) to the dispositional states of mind in those who are doing the inquiring. In those situations where there are settled outcomes, I have expressed my support for Metcalfe and Game's claim (cited in Scholl 2010) that 'Good teachers ... know the set curriculum outcomes, but suspend desire for these ... allowing them to be rediscovered through [genuine] inquiry...' (p. 6). Accordingly, when it comes to subjects whose outcomes are settled (by experts and, in turn, in the minds of teachers), teachers do not need to regard their role as one of 'persuading' students of the outcomes (using Hand's preferred term); rather they can feel confident that as long as students adhere to the proper procedures relating to the inquiry in question, they will, inevitably, arrive at these outcomes themselves. Yet just such persuasion is advocated by Hand, which is why he labels the teaching involved as 'directive'. Indeed, he maintains that teachers who fail to be directive, in the particular case of moral inquiry when there are settled outcomes, may well be involved in a 'dereliction of educational duty' (2020, p. 15).

Hand is claiming that directive or persuasive teaching is warranted if and only if the outcomes are settled, and that teachers can still engage the tools of inquiry as part of this persuasion. My response is that as long as students are equipped with both the dispositions and the tools appropriate to inquiry (in the relevant subject area), teachers do not need to be persuasive. Granted, some students may misapply these tools (just as some may lack the appropriate dispositions) and, therefore, run the risk of arriving at false conclusions. However, a community of inquiry is well-equipped to accommodate such situations. If it is a mature CoI, then the inquiry process, being largely in the hands of the students themselves, will provide correction or, at the very least, call attention to the problem ('I don't think that follows', 'I don't agree because ...', etc.). If, on the other hand, the $\mathrm{CoI}$ is still in the early stages of formation - and this is a matter of judgement by both teachers and students - then the teacher does, indeed, have a pedagogic responsibility to intervene ('Let's just review what Robin said/did', 'Does anyone have any questions for Robin?', etc.). It may well be that the teacher's sense that things have gone awry is driven by the realisation that the inquiry is heading in the wrong direction -i.e. toward answers or viewpoints which she knows to be unjustified or mistaken-and that the intervention is a form of persuasion ('Let's think about that again'), but this is not the kind of content-driven or directive persuasion to which Hand is referring. The latter risks subverting the 
inquiry process if students perceive that the teacher is 'pushing' them toward the 'right' answer.

\section{Indoctrination}

Hand rejects the claim, commonly made in the context of philosophy for children and CoI, that the teacher's (declared) endorsement or encouragement-i.e. persuasion - of particular moral beliefs or standards is a form of indoctrination. I am inclined to agree, because I share Hand's characterisation of indoctrination in terms of outcomes, as 'bring[ing] it about that they hold beliefs on some other basis than relevant evidence and argument' (p. 9). Accordingly, as long as students can justify their beliefs on the basis of relevant evidence and argument, they cannot be indoctrinated (even if someone intends or attempts to ind octrinate them). However, I submit that the kind of directive or persuasive teaching that Hand endorses could well result in some form of indoctrination in the situation alluded to in the previous paragraph, where contentdriven persuasion pushes students toward the right answer. Indeed, it is precisely in the moral domain where this is most likely.

Children acquire many of their moral beliefs, attitudes and values as a result of their everyday experiences and encounters with others, particularly significant others. Accordingly, they bring these ideas into the classroom, regardless of whether they are well thought out, reasonable, justified, etc. Hand may claim that it is just this scenario that demands the kind of directive moral education he endorses. My view, however, it is this very scenario that demands a non-directive but pedagogically strong inquiry-based approach, one which is, moreover, highly sensitive to/respectful of the views that children already have. As various scholars have pointed out, our most entrenched subjective convictions are the most difficult to shift; to the extent that they were not formed on the basis of reasoned argument, they are unlikely to respond to it. ${ }^{3}$ Our best hope is to help young people develop both the dispositions and tools of inquiry so that they - preferably in collaboration with their peers - will apply these to their own thinking. ${ }^{4}$

\section{Self-effacement and epistemic equality}

\footnotetext{
For example, Haidt 2012.

4 I develop this idea in my book (in progress) on identity, persons, morality, narrative and education.
} 
Hand also rejects the idea that such familiar phrases as 'pedagogically strong but philosophically self-effacing' rule out directive or persuasive teaching which guides 'pupils toward the answers to moral questions'. Like many others, I have long reflected on the meaning of such phrases, arguing that the balance between procedural and content-related 'strength' in a CoI depends, in large part, on the level of maturity it exhibits (as I noted earlier, the pedagogic responsibility is shared by the community itself as it matures). Like Hand, I am uneasy about a term like 'neutrality' which is sometimes how 'self-effacing' is interpreted, but my concern is that neutrality is consistent with a kind of substantive emptiness, where the teacher has no real understanding of the subject matter and just knows how to be pedagogically strong (perhaps by asking good 'procedural' questions). To the contrary, good teachers in a particular subject area cannot be pedagogically strong unless they have a strong understanding of their subject.

Hand also takes issue with the view that the participants in a CoI-of which the teacher is one-should be epistemically equal, in the sense that a stranger observing the CoI would be unable to distinguish the teacher from the students (age differences aside). Once again, I am sympathetic to Hand's view here, having observed many socalled communities of philosophical inquiry in which students are left to flounder around while making very little actual substantive progress. This being said, I would add, once again, that much depends on the level of maturity of the community. In mature CoIs, teachers are more able to participate as co-inquirers, because their pedagogical expertise is now shared by other members.

I suspect that Hand would not be entirely happy with my response here, since he insists that there really is a difference between a classroom CoI - whose members are, relatively speaking, novices in the subject being taught-and an expert CoI-whose members are working at the boundaries of their discipline. Only the latter exhibits true epistemic equality. In support of this distinction, Hand cites the work of historian Peter Seixas, whose seminal publication on CoI is particularly noteworthy, precisely because it is not explicitly related to philosophy or philosophy for children. Hand's citation of Seixas includes: 'First, a teacher is responsible for structuring the learning experiences of the classroom members ... Ultimately, the teacher is responsible for negotiating the form and content of cultural authority imposed from beyond the classroom ...' (Hand 2020, p. 16). My interpretation of Seixas's words here is, roughly, that teachers are responsible for constructing or, at least, managing, what students do in the classroom, and how the latter deal, both procedurally and substantively, with what is presented to them from outside the classroom. Is Seixas endorsing the kind of 
persuasive or content-directed teaching advocated by Hand (leaving aside that the former is not referring specifically to moral education)? I am not convinced that he is but, then, I am not sure.

\section{Back to moral/ethical inquiry}

I want, finally, to return to the domain of moral inquiry, as defined by Hand; in particular his distinction between justified/unjustified moral standards and controversial moral standards, as well as his view on how this distinction should be reflected by how teachers teach (in the context of a CoI). ${ }^{5}$ Hand does not have much to say about teaching controversial moral standards since, as he puts it, 'the nondirective aims appropriate to teaching controversial moral standards harmonise perfectly with the CoI method' (2020, p. 7). He also states that 'The teaching of controversial moral standards is nondirective, because the teacher refrains from persuasion and tries only to acquaint pupils with the arguments on each side' (2020, pp. 6-7). However, while this kind of approach might be appropriate in a university course on ethics/morality - in which students compare different normative theories and examine the meanings of key ethical/moral concepts, for example - it does not suffice in a CoI with youngsters. We would agree that the discipline of inquiry in both cases is philosophy, but as I hinted at earlier, moral education - which is the business of the classroom CoI-aims both to equip students with the tools of ethical inquiry, and to empower them to formulate their own views, beliefs and values in collaboration with others, while remaining open to criticising and modifying these same views. Fortunately, Hand does provide a more expansive formulation which goes some way toward addressing this additional component: 'When teaching controversial moral standards (e.g. do not eat meat; vote in democratic elections), they will aim to bring it about that pupils understand the arguments for and against subscription and can form considered views on them' (2020, p. 6, emphasis added).

Still, Hand appears to accept that the fact that some standards are controversial exempts teachers from the responsibility of judging them on the basis of their own standards or, indeed, anyone else's. He does not allow this exemption when it comes to teaching moral standards that are either justified or unjustified-hence his arguments in defence of directive teaching in such cases. But does the distinction

5 I acknowledge Hand's reference to his previously published book on this issue. Still, readers of the present paper should be able to take it on its own merits. 
between controversial and uncontroversial standards constitute adequate grounds for making his pedagogical case? I think not.

A brief examination of the examples offered by Hand will, I think, suffice to undermine this distinction. On the one hand, he offers not eating meat and voting in democratic elections as controversial standards; on the other, he offers not cheating, keeping promises, not masturbating, and engaging in homosexual acts as uncontroversial (with the first two being justified and the final two unjustified). But who determines the status of such examples, noting that this status has two dimensions: an empirical one (controversial versus uncontroversial) and a normative one (justified versus unjustified)? Compulsory voting in Australia is not legally controversial and, some might claim, it has become more or less accepted by society, i.e. uncontroversial. Conversely, ask young people if they think that cheating or not keeping promises is ever justified - not just as regarded by society but justified in their eyes - and they might come up with some quite creative possibilities (when promising to a tyrant, or cheating in order to save a life, for example). As for the uncontroversial status of certain sexual acts, this seems both culturally and time relative. Such acts are quite controversial in some religious contexts; indeed, in many countries, homosexual acts remain morally and legally proscribed, even condemned: so not controversial at all! Likewise in the case of most Western societies prior to the last sixty years or so. If we want a more contemporary example, consider the morality of same-sex marriage, whose status - both empirical and normative - is still changing. It might seem that I am appealing to some version of moral relativism here, but I am not. I am merely pointing out that in the moral domain, what is regarded as controversial does shift culturally and temporally, even though we might believe-indeed, I do-that such sexual prohibitions are and always were quite unjustified. Consider the predicament of a teacher at a time or in a place where homosexual acts are regarded as uncontroversial and unjustified. To what standard should she teach? Does it even matter to her role as a responsible teacher what standard she, herself, subscribes to (if any)? At the beginning of this paper, I asked 'What is the word "standards" doing in the formulation of moral inquiry?' I have argued at some length that it does not need to-indeed, should not-be there. Reflecting on Hand's own examples supports this position. Teachers conducting a community of moral inquiry should understand, enact and model the procedures of inquiry, regardless of the dominant status quo on moral standards that prevails in the society around them.

\section{References}


Cam, P (2006) 20 thinking tools: Collaborative inquiry for the classroom. ACER, Camberwell, Vic.

Haidt, J (2012) The righteous mind: Why good people are divided by politics and religion. Vintage Books, New York, NY.

Hand, M (2020) Moral education in the community of inquiry. Journal of Philosophy in Schools, (7)2, pp. 4-20.

Lipman, M (2003) Thinking in education. 2nd edn. Cambridge University Press, Cambridge, UK.

Scholl, R (2010) The Question Quadrant: A stimulus for a negotiated curriculum. Primary E Middle Years Educator, 8(2), pp. 3-16.

Splitter, LJ (2016) The dispositional ingredients at the heart of questioning and inquiry. Journal of Philosophy in Schools, 3(2), pp. 18-39.

Splitter, LJ (2020) Reflecting and looking forward: Inquiring into inquiry, philosophy and community. Analytic Teaching and Philosophical Praxis, 40(1), pp. 1-14. 